\title{
Niet erkend fiscaal kapitaal in internationale verhoudingen
}

Fusio-agio in de dividendbelasting

\section{Drs. G. M. M. Michielse}

\section{Historie}

Tijdens de parlementaire behandeling van het wetsontwerp Oort-1 ${ }^{1}$ werd, vrij onverwacht, door CDA-Kamerlid Vreugdenhil een amendement ingediend tot wijziging van artikel 3 van de Wet op de Dividendbelasting 1965 (Wet Div.). ${ }^{2}$ Dit amendement hield in dat artikel 3 Wet Div. wordt uitgebreid met een tweede lid: 'De artikelen 44 en 80 van de Wet op de Inkomstenbelasting 1964 zijn van overeenkomstige toepassing.' Het amendement is door de Tweede Kamer unaniem aanvaard.

Tijdens de behandeling van het wetsontwerp Oort-I zijn echter in de Eerste Kamer kritische vragen gesteld ten aanzien van dit amendement. Om te voorkomen dat het totale wetsontwerp zou worden verworpen, heeft de staatssecretaris van Financiën door middel van een resolutie ${ }^{3}$ de toepassing van deze bepaling enigszins versoepeld. In dit artikel beperk ik mij tot de bespreking van de positief-rechtelijke aspecten van de, inmiddels in werking getreden, regeling.

\section{Artikel 44 en 80 van de Wet op de Inkomstenbelasting 1964}

Alvorens de specifieke fiscale gevolgen binnen de Wet op de Dividendbelasting te bespreken, is het nuttig eerst de werking van artikel 44 Wet IB nader te bezien.

Artikel 44 Wet IB geeft de fiscus de wettelijke garantie dat bij een aandelenfusie de latente IB- claim op de winstreserves in stand blijft. Artikel 80 Wet IB beperkt deze regeling tot aandelenfusies die op of na 1 januari 1946 tot stand zijn gekomen. De latente IB-claim op de winstreserves berust op het in het Nederlandse belastingrecht neergelegde uitgangspunt dat de waarde van de kapitaalvennootschap, voor zover deze het gestorte kapitaal te boven gaat, vroeg (bij uitdeling) of laat (uiterlijk bij liquidatie) met inkomstenbelasting behoort te worden belast. Daarentegen wordt een teruggave van hetgeen op aandelen is gestort in het algemeen niet als een uitdeling in aanmerking genomen. Om misbruik te voorkomen, heeft de wetgever in artikel 29 Wet IB echter een bepaling geïntroduceerd, die erop neerkomt dat:

- een (gedeeltelijke) terugbetaling van het nominaal gestort kapitaal als dividend-uitkering wordt aangemerkt indien en voor zover er zuivere winst (winstreserves of toekomstige winstverwachting) aanwezig is, tenzij het nominale kapitaal ook statutair wordt verminderd.

- een (gedeeltelijke) terugbetaling van agio of informeel kapitaal als dividend-uitkering wordt beschouwd indien en voor zover er zuivere winst is.

Een en ander heeft ook gevolgen voor de liquidatie. De liquidatie-uitkering zal gesplitst moeten worden in een terugbetaling van gestort kapitaal

Drs. G. M. M. Michielse is universitair docent internationaal belastingrecht aan het Fiscaal Instituut Tilburg, tevens als belastingadviseur verbonden aan Loyens \& Volkmaars te Rotterdam. 


\section{MAB}

en een winstuitdeling. Het gemiddeld op de aandelen gestorte kapitaal vormt hierbij het beslissende criterium. De vaststelling van het fiscaal erkende gestorte kapitaal is derhalve in ons belastingrecht van wezenlijke betekenis.

In de literatuur ${ }^{4}$ wordt aangenomen dat alle stortingen door de aandeelhouders in geld of goederen, anders dan bij wijze van geldlening, het gestorte kapitaal verhogen. Indien de aandeelhouder de aandelen van vennootschap $A$ verwerft door inbreng van de aandelen in vennootschap $B$ ('aandelen-fusie'), wordt het gestorte kapitaal van vennootschap $A$ vermeerderd met de waarde in het economische verkeer van de aandelen in vennootschap $B$. Het resultaat zou zijn dat de winstreserves van vennootschap $\mathrm{B}$ bij uitdeling niet langer worden getroffen door inkomstenbelasting, maar - al dan niet als gevolg van de deelnemingsvrijstelling - belastingvrij door vennootschap A zouden kunnen worden gerealiseerd. Vervolgens zou vennootschap $A$ de ontvangen liquiditeiten kunnen gebruiken om een overeenkomstig gedeelte van het gestorte kapitaal aan de aandeelhouder terug te betalen, zonder dat dit voor deze laatste fiscale gevolgen met zich mee behoeft te brengen. Het volgende voorbeeld moge dit verduidelijken:

Vennootschap B heeft 100.000 nominaal kapitaal en 400.000 winstreserves. Bij uitdeling van de winstreserves aan de aandeelhouder wordt 400.000 getroffen met inkomstenbelasting.

Indien de aandeelhouder echter eerst de aandelen $B$ inbrengt in een vennootschap $A$ en daarvoor aandelen $A$ verwerft, zal de uitdeling van de winstreserves door vennootschap $B$ aan vennootschap A geen belasting oproepen (afboeking van het meegekochte dividend). De oorspronkelijke winstreserves van vennootschap $B$ zijn nu immers omgezet in kapitaal bij vennootschap $A$, waartegenover een deelneming in $B$ wordt geactiveerd. Vennootschap A heeft een gestort kapitaal van 500.000 en kan besluiten tot een terugbetaling van kapitaal ter grootte van 400.000. Een dergelijke terugbetaling geschiedt belastingvrij, mits de statuten worden aangepast.

Artikel 44 Wet IB verhindert nu deze mogelijkheid om belastbare winstuitdeling om te zetten in onbelaste terugbetaling van kapitaal. Indien sprake is van een kapitaalinbreng in de vorm van aandelen, erkent de fiscus slechts als gestort kapitaal van de overnemende vennootschap (in het voorbeeld: vennootschap A) het gestorte kapitaal op de ingebrachte aandelen (in het voorbeeld: aandelen in vennootschap $B$ ). In het voorbeeld heeft vennootschap $A$ derhalve slechts een fiscaal erkend kapitaal van 100.000 en vormt de terugbetaling van 400.000 een belaste dividenduitkering.

\section{Dividendbelasting}

De Wet op de Dividendbelasting 1965 bevatte tot 28 april 1989 geen bepaling die belastingheffing verzekerde op uitkering van het fiscaal niet erkende kapitaal. Het was derhalve omstreden of artikel 44 Wet IB ertoe zou kunnen leiden dat een terugbetaling van niet erkend kapitaal dividendbelasting tot gevolg zou kunnen hebben. Deze vraag is inmiddels door de Hoge Raad negatief beslist. $^{5}$ Door de introductie van het nieuwe tweede lid van artikel 3 Wet Div. is dit arrest voor terugbetalingen van kapitaal na 28 april 1989 zonder betekenis.

Voor de binnenlandse aandeelhouders (rechtspersonen en natuurlijke personen) heeft de dividendbelasting het karakter van een voorheffing. De verschuldigde dividendbelasting kan worden verrekend met de inkomsten- of vennootschapsbelasting. De introductie van artikel 3, lid 2 Wet Div. heeft voor deze groep slechts een liquiditeitseffect. De heffing over de - als dividend gekwalificeerde - terugbetaling van kapitaal wordt immers vervroegd naar het moment waarop de terugbetaling geschiedt. Daarentegen vormt de dividendbelasting voor de buitenlandse aandeelhouders een definitieve heffing. (Deze heffing wordt onder de werking van verdragen ter voorkoming van dubbele belasting in het algemeen gereduceerd en in sommige situaties zelfs geheel achterwege gelaten.) Voor deze categorie aandeelhouders betekent de nieuwe bepaling derhalve een belastingverzwaring.

Tegen deze buitenlandse aandeelhouders was ook het amendement gericht. In de praktijk kwam 
het voor dat 'vette' buitenlandse vennootschappen (dat wil zeggen vennootschappen met enorme winstreserves) in een Nederlandse holdingmaatschappij werden ingebracht met het doel een zo hoog mogelijk gestort kapitaal te creëren. Hierdoor ontstond dan de mogelijkheid gedurende een bepaalde periode winsten te reserveren, doch in dezelfde omvang kapitaal terug te betalen (belastingvrij voor de buitenlandse aandeelhouders).

Artikel 3, lid 2 Wet Div. bevat echter een overkill. Indien de aandelen in een buitenlandse vennootschap worden ingebracht in een Nederlandse vennootschap tegen uitgifte van aandelen, komen de reeds aanwezige winstreserves in die buitenlandse vennootschap onder de Nederlandse dividendbelasting-claim. Niet deze winstreserves zouden moeten worden getroffen door een dergelijke claim, maar de winsten die na de aandeleninbreng door de buitenlandse vennootschap worden gerealiseerd. Bovendien zou een dergelijke claim in strijd zijn met de internationale opvattingen omtrent de heffing van ondernemingswinsten. ${ }^{6}$

\section{Uitvoeringsresolutie}

De staatssecretaris heeft, onder druk van de Eerste Kamer, bij resolutie ${ }^{7}$ deze overkill verzacht en geregeld dat:

- bij inbreng van de aandelen in een buitenlandse vennootschap in een Nederlandse vennootschap de waarde in het economische verkeer (inclusief stille reserves en goodwill) van de ingebrachte aandelen wordt aangemerkt als het fiscaal erkend kapitaal van de Nederlandse vennootschap. Deze methode wordt ook aangeduid als de 'opstapmethode'.

- bij terugbetaling door of liquidatie van de Nederlandse vennootschap de uitkering als dividenduitkering wordt beschouwd, indien en voorzover de buitenlandse vennootschap bij aanwezigheid van winsten behaald na de aandeleninbreng uitkeringen aan de Nederlandse vennootschap heeft doen toekomen. Deze toerekening vindt plaats op grond van de LIFOmethode. Opgemerkt moet worden dat de allocatie plaatsvindt per buitenlandse vennoot- schap en geheel naar het inzicht van belastingplichtige.

De werking van deze resolutie kan door een belastingplichtige uitsluitend op verzoek worden ingeroepen. Daarbij dient de belastingplichtige gegevens te overleggen die het mogelijk maken de waarde in het economische verkeer ten tijde van de inbreng vast te stellen (waarderingsrapport accountant) en tevens dient de belastingplichtige een verklaring af te geven dat alsnog dividendbelasting verschuldigd wordt, indien binnen 12 maanden na terugbetaling toch gelden aan de buitenlandse vennootschap ter beschikking worden gesteld. De ratio van deze voorwaarde is door de staatssecretaris niet gegeven.

Een voorbeeld: De buitenlandse vennootschap B heeft 100.000 nominaal kapitaal en 400.000 winstreserves. De buitenlandse aandeelhouder verwerft alle aandelen in de Nederlandse vennootschap $A$ door inbreng van de aandelen in vennootschap $B$ en besluit vervolgens onmiddellijk tot uitdeling van de winstreserves aan vennootschap A. Vennootschap A heeft een gestort kapitaal van 500.000 (waarde in het economische verkeer) en kan dus besluiten tot een terugbetaling van kapitaal voor een bedrag van 400.000 . Een dergelijke terugbetaling geschiedt zonder heffing van dividendbelasting.

$\mathrm{Nu}$ wacht vennootschap B met de uitkering van de winstreserves tot het volgende jaar. Inmiddels heeft zij een winst gerealiseerd van 100.000. Wederom besluit zij de 400.000 winstreserves uit te keren aan vennootschap $A$, die op haar beurt dit bedrag als kapitaalterugbetaling aan haar aandeelhouder wenst toe te laten komen. Nu stelt de resolutie echter dat eerst 100.000 moet worden toegerekend aan de winst behaald door vennootschap B na de aandeleninbreng en dus als dividenduitkering van vennootschap $A$ aangemerkt dient te worden! De resterende 300.000 kunnen als terugbetaling van kapitaal vrij van dividendbelasting door de aandeelhouder worden gerealiseerd.

\section{De term 'uitkeringen'}

De kwalificatie van een (gedeelte van de) terugbe- 


\section{MAB}

taling van het kapitaal als dividenduitkering kan alleen geschieden indien sprake is van 'uitkeringen' door een buitenlandse dochtermaatschappij, die commerciële winst ${ }^{8}$ heeft gerealiseerd na de aandeleninbreng. De term 'uitkeringen' wordt door de staatssecretaris niet nader omschreven.

Uit de brief aan de Voorzitter van de vaste Commissie voor Financiën uit de Eerste Kamer der Staten-Generaal ${ }^{9}$ blijkt echter dat hij hiermee winstuitkeringen bedoelt. Dit betekent dat indien de buitenlandse vennootschap kapitaal terugbetaalt in plaats van winst uitkeert, een terugbetaling van kapitaal door de Nederlandse vennootschap niet als dividend kan worden beschouwd.

\section{De aanwezigheid van commerciële winst na de aandeleninbreng}

Om te beoordelen of een terugbetaling van kapitaal door de Nederlandse holdingvennootschap als dividend moet worden beschouwd, heeft de staatssecretaris als criterium aangelegd het feit dat de buitenlandse vennootschap na de aandeleninbreng commerciële winst heeft gerealiseerd. Dit kan met name tot vreemde gevolgen leiden bij liquidatie.

Stel dat een buitenlandse vennootschap de volgende commerciële én fiscale balans heeft:

per ultimo jaar 0

\begin{tabular}{lr|ll}
\hline activa-passiva & 500.000 & $\begin{array}{ll}\text { nom. gest. kapitaal } \\
\text { winstreserves }\end{array}$ & $\begin{array}{l}100.000 \\
\text { w00.000 }\end{array}$ \\
\cline { 2 - 3 } & & & \\
& & &
\end{tabular}

Werkelijke waarde: 1.000 .000 (incl. 300.000 stille reserves en 200.000 goodwill)

De fiscale balans van de Nederlandse holding na inbreng van de aandelen in deze buitenlandse vennootschap luidt:

per ultimo jaar 0

\begin{tabular}{ll|l}
\hline deelneming $\frac{1.000 .000}{1.000 .000}$ & nom. gest. kapitaal $\frac{1.000 .000}{1.000 .000}$
\end{tabular}

In jaar 1 lijdt de buitenlandse vennootschap een commercieel verlies van 100.000 . Als in jaar 2 blijkt dat de goodwill ook geheel verdwenen is, besluit de Nederlandse holding haar buitenlandse dochtermaatschappij te liquideren. De liquidatieuitkering bedraagt 700.000. De stille reserves zullen als commerciële winst worden gerealiseerd. ${ }^{10}$ Indien de Nederlandse holding vervolgens besluit tot terugbetaling van kapitaal aan haar aandeelhouder, wordt Nederlandse dividendbelasting verschuldigd: de buitenlandse vennootschap doet immers een uitkering en heeft commerciële winst gerealiseerd na de aandeleninbreng. ${ }^{11} \mathrm{Het}$ resultaat is dat de Nederlandse fiscus alsnog - via de achterdeur - belasting heft over de bij de aandeleninbreng reeds aanwezige, in het buitenland opgebouwde, reserves! Dit kan niet de bedoeling zijn geweest. Uitgangspunt mag derhalve niet zijn de aanwezige commerciële winst, maar de commerciële winst, voor zover niet gerealiseerd door de stille reserves die reeds aanwezig waren op het moment van de aandeleninbreng.

\section{De allocatie van de commerciële winst}

In de uitvoeringsresolutie heeft de staatssecretaris gesteld dat de LIFO-methode geldt voor elke dochtervennootschap afzonderlijk. De belastingplichtige heeft daarbij de keuzemogelijkheid om de ontvangen uitkering, die wordt gebruikt voor de terugbetaling van kapitaal, toe te rekenen aan één van haar dochtervennootschappen. Daarbij kan worden gekozen tussen dochtermaatschappijen die een uitkering aan de Nederlandse vennootschap hebben gedaan. ${ }^{12}$

\section{Een voorbeeld:}

Stel dat een Duitse vennootschap besluit tot een joint-venture met een Deense vennootschap. De joint-venture zal worden uitgeoefend in een Nederlandse BV, waarbij zowel de Duitse vennootschap als de Deense vennootschap de aandelen van een dochtermaatschappij inbrengen. De waarde in het economische verkeer van de aandelen in de Duitse vennootschap bedraagt 750.000 , terwijl de aandelen in de Deense vennootschap een waarde van 250.000 hebben. Het gestorte kapitaal van de Nederlandse joint-ven- 
ture bedraagt derhalve 1.000.000. Na de inbreng kan de structuur als volgt worden weergegeven: (zie figuur)

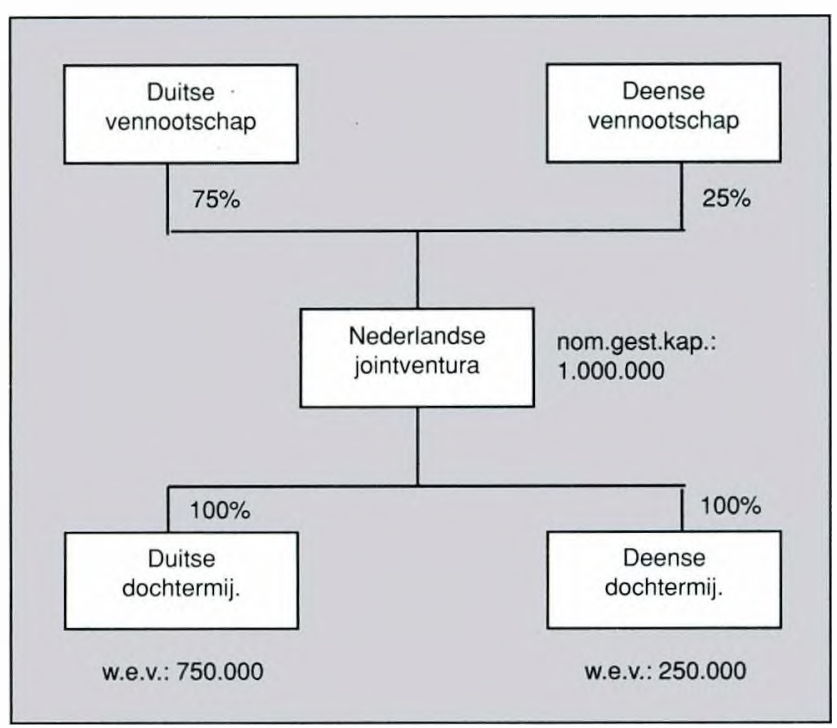

In het eerste jaar na deze aandelenfusie realiseert de Duitse dochtermaatschappij een commerciële winst van 50.000. In het tweede jaar wordt door elk van de dochtermaatschappijen 200.000 aan de Nederlandse vennootschap uitgekeerd. Vervolgens besluit de Nederlandse joint-venture de helft (dus 200.000) te gebruiken voor een terugbetaling van kapitaal aan haar aandeelhouders.

In beginsel zijn er nu twee mogelijkheden voor de Nederlandse joint-venture:

1 De benodigde liquiditeiten voor de terugbetaling van kapitaal worden toegerekend aan de Deense dochtermaatschappij. Deze dochtermaatschappij heeft na de aandeleninbreng géén commerciële winst gerealiseerd. De terugbetaling wordt derhalve geheel toegerekend aan de reeds voor de inbreng aanwezige winstreserves. Het resultaat is dat de terugbetaling zonder dividendbelasting kan geschieden.

2 De benodigde liquiditeiten voor de terugbetaling van kapitaal worden toegerekend aan de Duitse dochtermaatschappij. Deze dochtermaatschappij heeft na de aandeleninbreng wel commerciële winst gerealiseerd. De terugbetaling van kapitaal roept als gevolg van de LIFO- methode een dividendbelasting op over 50.000. De resterende 150.000 wordt toegerekend aan de reeds voor de inbreng aanwezige winstreserves.

In deze laatste situatie is vervolgens de vraag hoe de toerekening aan de aandeelhouders plaatsvindt. Hier zijn drie verschillende visies mogelijk:

a De als dividend gekwalificeerde terugbetaling van kapitaal wordt aan de Duitse aandeelhouder toegerekend. Hij ontvangt 150.000 , waarvan 50.000 als dividend wordt aangemerkt. Onder het Nederlands-Duitse belastingverdrag wordt de dividendbelasting tot $10 \%$ gereduceerd. ${ }^{13}$

b De als dividend gekwalificeerde terugbetaling van kapitaal wordt aan de Deense aandeelhouder toegerekend. Hij ontvangt 50.000 dat geheel als dividend wordt aangemerkt. Onder het Nederlands-Deense belastingverdrag wordt de dividendbelasting tot nihil gereduceerd. ${ }^{14}$

c De als dividend gekwalificeerde terugbetaling van kapitaal wordt pro rata aan de Duitse en Deense aandeelhouder toegerekend. De Duitse aandeelhouder ontvangt derhalve 150.000, waarvan 37.500 als dividend wordt behandeld. De Deense aandeelhouder ontvangt 50.000 , waarvan 12.500 als dividend wordt behandeld.

Indien een (gedeelte van de) terugbetaling van kapitaal als dividend wordt aangemerkt, doet zich dus de vraag voor aan welke aandeelhouder dit dividend toe te rekenen valt. De resolutie zegt hierover niets. De hierboven besproken mogelijkheid (c) lijkt theoretisch het meest juist. Doch in geval meerdere soorten aandelen bestaan, kunnen ook (a) en (b) niet geheel worden uitgesloten.

In zo'n situatie ontstaat voor belastingplichtige een aardige planningsmogelijkheid, waarbij de toerekening van de als dividend gekwalificeerde terugbetaling van kapitaal aan de aandeelhouders afhankelijk is van de hoogte van de toegestane bronheffingspercentages op dividenden zoals geregeld in het belastingverdrag waarop deze aandeelhouders een beroep kunnen doen. 


\section{MAB}

\section{Conclusie}

De uitvoeringsresolutie van de staatssecretaris na invoering van artikel 3, lid 2 Wet Div. verzacht de negatieve effecten voor internationale concerns door introductie van een 'step-up' bij de aandeleninbreng en heeft bovendien geleid tot een complexe toerekeningssystematiek. De overkill bij liquidatie van een buitenlandse dochtermaatschappij is echter nog steeds niet geheel opgelost. Dit wordt veroorzaakt doordat de 'opstapmethode' slechts bij inbreng van aandelen wordt gehanteerd, terwijl bij de terugbetaling geen rekening wordt gehouden met de stille reserves die nog niet in de commerciële winst tot uitdrukking zijn gekomen.

\section{Noten}

1 Tweede Kamer, vergaderjaar 1988-1989, 20595.

2 Tweede Kamer, vergaderjaar 1988-1989, 20595, nr. 48.

3 Resolutie 17 augustus 1989, nr. DB89/4235; V-N, 31 augustus 1989 , p. 2457, nr. 21, alsmede de brief aan de Voorzitter van de vaste Commissie voor Financiën uit de Eerste Kamer der StatenGeneraal, V-N, 13 april 1989, p. 1093, nr. 21.

4 Onder andere Prof. Dr. J. C. K. W. Bartel,

Inkomstenbelastingaspecten van de opbrengst van aandelen,

Fiscale Monografieën, nr. 29.
5 Hoge Raad 25 oktober 1989, BNB 1990/35.

6 Onder andere met de internationale toewijzing van belastingheffing over winsten aan de bronstaat (artikel 7 OECDmodelverdrag)

7 Zie noot 3.

8 In de slotzin van de Resolutie wijst de staatssecretaris erop dat 'door de buitenlandse vennootschap na de aandelenfusie behaaide winst' dient te worden opgevat als commerciële winst. 9 Brief van 28 maart 1989, ais bijlage opgenomen in de resolutie van 17 augustus 1989, nr. DB89/4235.

10 De stille reserves verschijnen als commerciële winst in de boeken omdat de buitenlandse vennootschap commercieel heeft gewaardeerd op historische kostprijs. Dit zou bijvoorbeeld een gevolg kunnen zijn van de nationale wetgeving.

In de Bondsrepubliek bijvoorbeeld leidt een commerciële waardering tegen actuele waarden op grond van het 'Maßgeblichkeitsprinzip' tot het fiscaal realiseren van de herwaarderingswinst.

11 Pieter M. Smit, The Vreugdenhil Amendment, in: 'European Taxation', July 1989, blz. 234, komt in dit verband tot een tegenovergestelde conclusie. Indien de commerciële waardering plaatsvindt op basis van de actuele waarden is deze conclusie juist. In buitenlandse jurisdicties, waar de commerciële winst echter op basis van historische kosten wordt vastgelegd, kan n.m.m. een liquidatie-winst echter evenzeer tot de commerciële winst behoren en tot herkwalificatie van de terugbetaling van kapitaal door de Nederlandse holding leiden.

12 In de Brief behorende bij de Resolutie (zie noot 3) spreekt de staatssecretaris van 'dooruitdeling'.

13 Artikel 13, lid 4 van het Nederlands-Duitse verdrag.

14 Artikel 9, paragraaf 3 van het Nederlands-Deense belastingverdrag. 